\title{
How to Improve A Mathematics Teacher's Ways of Triggering and Considering Divergent Thoughts through Lesson Study
}

\author{
Aytug Ozaltun Celik ${ }^{1}$, Esra Bukova Guzel 2*
}

\author{
${ }^{1}$ Pamukkale University, TURKEY \\ ${ }^{2}$ Dokuz Eylul University, TURKEY \\ * CORRESPONDENCE: $\gg$ esra.bukova@deu.edu.tr
}

\begin{abstract}
In this study, we aimed to examine a mathematics teacher's actions related to triggering and considering divergent thoughts on the lessons before, during, and after the lesson study process. The participant was a mathematics teacher who participated in a lesson study design. We focused on his lessons before, during, and after the lesson study. The data were collected from the teacher's lessons and these lessons were videotaped. The transcripts of these video records were analyzed in the context of triggering and considering divergent thoughts. The teacher's actions were interpreted and the evidences were provided from the excerpts of the lessons. Throughout the lesson study, the teacher's actions related to considering students' thinking were improved and also varied. We suppose that this study will be a guide for mathematics teachers and teacher educators on triggering and considering divergent ideas.
\end{abstract}

Keywords: divergent thoughts, knowledge of student thinking, lesson study

\section{INTRODUCTION}

Having knowledge of content and student that allows teachers to focus on their understanding of how students learn a particular content (Hill, Ball, \& Schilling, 2008) requires estimating students' thinking, and considering them during teaching. Knowledge of Student Thinking (KoST) includes knowing students' understandings, learning processes, difficulties, and mistakes (Marks, 1990). Teachers having KoST take students' cognitive and social aspects into consideration during teaching and help students learn by identifying effective strategies to encourage thinking. KoST is of great importance for teachers to have ideas what questions they should ask in their lessons and in which ways they may ask these questions and to support their students' actions in the classroom to make them challenging individuals in cognitive and social aspects. Pedagogical practices such as sharing work with learners, preparing discussion activities in small groups, or encouraging students to clarify ideas help teachers reflect their KoST (Van Zoest, Stockero, \& Kratky, 2010). Teachers who reflect their KoST into teaching provide students having the ability of explaining their thoughts and ideas, developing their thinking and problem solving skills, using multiple representations, and relating mathematical concepts to real life and other areas (Wicks \& Janes, 2006).

An, Kulm and Wu (2004) stated that the KoST provides teachers with the opportunities to develop their knowledge of content and curriculum, to plan their lessons in detail and to teach mathematics effectively. The researchers expressed KoST as addressing students' misconception, building on students' math idea, engaging students in math learning and promoting students' thinking mathematically. Lee (2006) extended the content of the KoST based on the study of An, Kulm and Wu (2004) and addressed the approach of "questioning triggering divergent idea" in the context of this knowledge. Questioning is a strategy that give opportunities

Article History: Received 26 April $2020 \bullet$ Revised 12 Jun $2020 \bullet$ Accepted 4 July 2020

(C) 2020 by the authors; licensee Modestum. Open Access terms of the Creative Commons Attribution 4.0 International License (http://creativecommons.org/licenses/by/4.0/) apply. The license permits unrestricted use, distribution, and reproduction in any medium, on the condition that users give exact credit to the original author(s) and the source, provide a link to the Creative Commons license, and indicate if they made any changes. 
for teachers to reveal students' thoughts and to allow them to determine the ways which students should be supported. Coffey, Edwards and Finkelstein (2010) observed a pre-service teacher during teaching process and determined that the pre-service teacher revealed students' strategies and thinking processes by questioning. By this way, they also stated that they supported students to use solution ways addressed in lessons and to share their strategies with each other while examining different solutions. Burns (1985) stated that the teachers should ask questions to eliminate the errors in the students' thoughts when the students gave incorrect responses and to expand their correct responses (as cited in Shahrill, 2013). Teachers' questions are only part of a context that allow students to develop their thoughts (Cengiz, 2007). Cengiz (2007) stated that teachers should encourage students to explain their solution methods, to think about alternative situations, to focus on missing parts of their inferences, to reason strategies for persuading their classmate, and to reflect on each other's thoughts.

When the literature is examined, it is seen that teacher actions that encourage students to think mathematically differently are not fully clear. In order to provide students have conceptual understanding, teachers require to consider students' thinking and to know how to do it. Besides, they require to know how to create environments enabling to students to discuss with each other about different ideas and thoughts in lessons. Teachers should have awareness about knowledge of students thinking in order to use these important actions in teaching. It is also important that teachers believe that their actions in lessons, which are evidences of knowledge of student thinking, are an important aspect in supporting students' conceptual understanding. In addition to explaining to teachers the necessity of changing teaching routines, it would be appropriate to incorporate them into professional development programs providing reasons why changes are necessary, how they can be achieved, and what results they will produce. In this respect, the importance of mathematics teachers' participation in long-term professional development programs, which are based on the development of knowledge of student thinking and based on their real classroom teaching, is emerging. Especially, the lesson study model, which requires long-term and cyclic teaching practices among the various professional development models, is effective in supporting the development of students thinking because the lesson study is focused on students in each stage of instruction.

It is known that lesson study which is one of the models addressing teachers' improvements has many properties of high-quality professional development (Perry \& Lewis, 2009). Lesson study is defined as a cycle in which teachers collaboratively plan a research lesson, and implement, observe and revise this lesson (Hurd \& Licciardo-Musso, 2005). Yoshida (1999) has explained actions to be performed during a lesson study process as making lesson plans, implementing these plans in classrooms, observing and reflecting the lessons, and stated that a lesson study cycle can be described as a series of meetings conducted with experts on the field. This process requires that different teachers collaboratively work, evaluate their teaching practices in terms of students and improve their teaching by discussing with each other. Thus, teachers notice effectiveness of lesson study. During lesson study process, teachers discuss students' different thoughts and consider possible students' approaches and ideas in planning meetings, thus they will use the opportunities to encourage students to think differently in teaching.

We designed a nine-month lesson study consisting of three cycles in which we examined the improvement of teachers' KoST accordance with the teaching evidences. Each cycle was composed of five stages (Özaltun Çelik \& Bukova Güzel, 2018): (a) research and planning, (b) implementing research lesson, (c) reflecting and improving research lesson, (d) implementing revision lesson, and (e) reflecting and improving revision lesson (See Figure 1). 


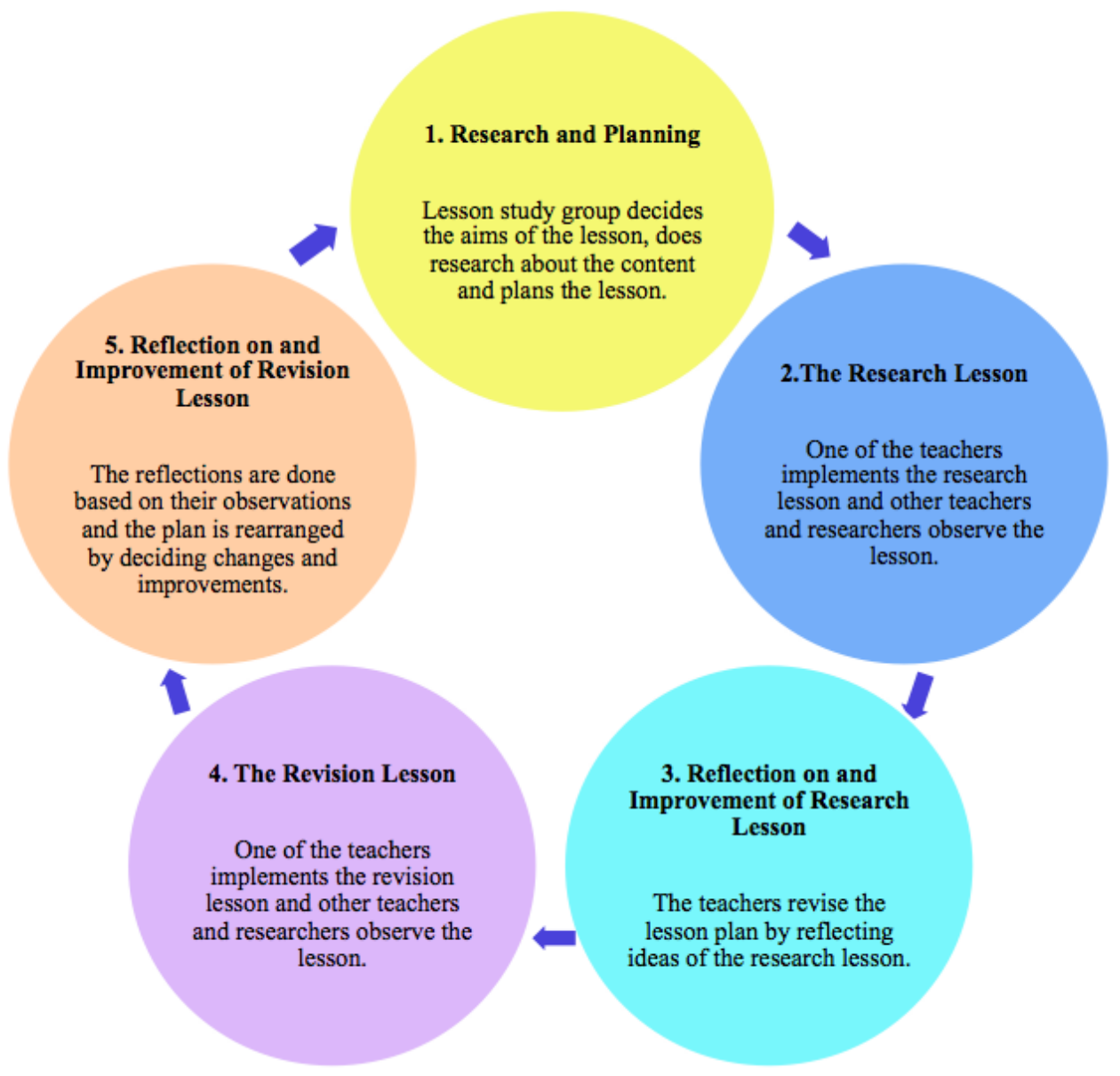

Figure 1. The cycle of lesson study in the study

In this process, we realized that, besides questioning, there were teachers' actions which were related to KoST and revealed different thoughts. While teachers' questions encourage students to think differently or to reason about various ideas, their different type of actions to contribute to the enrichment of the classroom environment by considering divergent ideas in the lessons. In parallel, Van Zoest, Stockero, and Kratky (2010) noted that teachers could understand their students' different thoughts by noticing various students' thinking and solution methods, trying to reveal their thoughts and encouraging the students to compare their ideas with others and to question each other. Additionally, it is important that teachers encourage learners to use their own strategies to solve problems, participate in dialogues that allow them to explain their thoughts, and discuss the reasons for their thoughts in order to increase the diversity of ideas in the classroom (Franke, Webb, Chan, Ing, Freund, \& Battey, 2009). Jensen (1976) suggested that prompting the students to find and use alternative or original solutions to problems developed students' problem-solving skills and different ideas (as cited in Fetterly, 2010). The lesson study process is important for teachers to improve the teachers' these actions. Because it helps teachers notice different students' thinking by observing and discussing their colleagues' lessons. Determining teachers' actions when engaged in the lesson study in terms of triggering and considering divergent thoughts and discussing them with the examples from their teaching may provide broad perspective for mathematics educators. Also, handling the evidences related to the content of KoST in the teaching process may give ideas to the mathematics teachers regarding their own teaching. Mathematics teachers or pre-service mathematics teachers may examine these examples in several professional development programs and thus they may be prompted to think divergent actions by reflecting them in their own teaching process. In this regard, the purpose of this study was to examine a mathematics teacher's actions related to triggering and considering divergent thoughts on the lessons before, during, and after the lesson study process. In the study, the three research questions were investigated. 
1. How are the mathematics teacher's actions on "triggering and considering divergent thoughts" before the lesson study?

2. How are the mathematics teacher's actions on "triggering and considering divergent thoughts" during the lesson study?

3. How are the mathematics teacher's actions on "triggering and considering divergent thoughts" after the lesson study?

\section{METHOD}

Since we aimed to examine how to reflect the mathematics teacher's actions related to triggering and considering divergent thoughts during his teaching in a detail way, we designed this study as a qualitative case study. We examined the teacher's actions as cases.

\section{The Participant}

The participant was a mathematics teacher (pseudonym named Ali) working at a high school in Turkey chosen by typical-case sampling of purposive sampling methods. The aim of the purposive sampling method is to obtain more information about the purpose and to choose the case which would provide useful information. By means of typical situation sampling, a general view may be gained through working on the average situations (Patton, 2002). Ali having thirteen-years of experience took a bachelor's degree in mathematics education and then a master's degree in mathematics. We conducted semi-structured interviews with him and observed his two-hour lessons in the beginning of the process. Thus, we had more information about him. Ali was trying to ask thought provoking questions to his students but he did not completely integrate these kinds of questions into his lessons. Sometimes, he was able to choose appropriate questions and examples. Yet, his pedagogical approaches were limited while he was practicing well-chosen questions. Also, he was not questioning the reasons for the incorrect solutions.

\section{Data Collection Process}

We first interviewed with the teacher to understand whether he had awareness regarding KoST and to determine their routines about lesson planning. Additionally, we observed his two-hours lesson to examine his actions and teaching approaches before the lesson study. In this lesson, Ali taught the topic of "finding the greatest common divisor (GCD) and least common multiple (LCM) of two or more polynomial functions" at the $10^{\text {th }}$ grade. Then, we gave seminars for the lesson study group to have ideas about KoST and to realize the need of reflecting this knowledge on teaching for effective teaching and conceptual learning. After these process, the lesson study group decided to teach "radical expressions" at $9^{\text {th }}$ grade in the first cycle of the lesson study, "the trigonometric ratios in a right-angled triangle" at $10^{\text {th }}$ grade in the second cycle and "coterminal angle and unit circle" at $10^{\text {th }}$ grade in the third cycle. While deciding these topics, they considered to conduct their lessons at different grade levels and different topics. The research lesson of the first cycle was conducted and all lessons in the other cycles were taught by Ali, because we had no chance of changing the teachers' schedules prepared by the school administration while the lesson study was going on. After the lesson study cycles, we observed Ali's lesson on the topic of "double angle formulas, product-to-sum and sum-to-product identities" at the $10^{\text {th }}$ grade. We observed the all lessons and recorded them by two video cameras. These video recordings were primary data for the study.

\section{Data Analysis}

In order to analyze the data, we transcribed the video recordings. We first independently started to examine the transcriptions in the context of the triggering and considering divergent ideas. When examining the transcriptions, we particularly focused on the parts where different ideas were triggered and examined the actions triggering different ideas. Then we came together and shared our individual analysis with each other. We reviewed the parts that we thought that the different thoughts were triggered on this process. After then, we discussed the reasons of differences regarding our individual coding and decided the final codes by reaching a consensus. As we carried out our analyses simultaneous to the lessons, we made retrospective analysis after all lessons for examining the data holistically. We also tried to determine the changes during the process in order to understand the effect of the lesson study in triggering different thoughts. Thus, we considered the teacher's approaches before, during and after the lesson study. The codes which we improved and revised during the study played an important role in conducting retrospective analysis. We made 
retrospective analyze based on the eight components of (1) ask questions to elicit students' ideas; (2) create class discussion about a student's idea/solution/question or any thoughts; (3) ask students to produce thoughts or to explain about teacher's expressions; (4) ask students to explain/expand/interpret about ideas proposed by them; (5) ask students to express each other's explanations in different ways; (6) ask students to give contradictory examples; (7) encourage students to produce different solutions; (8) explain/expand students' ideas. While presenting the evidences from the lessons in the section of results, we used the excerpts from the lessons. In these excerpts, we extracted the parts or speeches irrelevant to focus of the component.

\section{RESULTS}

We present the teacher's actions regarding "triggering and considering divergent thoughts" in three parts as before the lesson study, during the lesson study and after the lesson study.

\section{Before the Lesson Study}

Ali had several approaches related to the component of "triggering and considering divergent thoughts" during his teaching before the lesson study. He asked questions to understand the students' ideas about the concepts, explained their students' ideas and created a discussion environment to reveal students' possible thoughts. In the following excerpt, it can be seen that Ali asked them to explain their ideas and gave feedbacks about their ideas.

Board: $\quad$ Degree of $\mathrm{P}(\mathrm{x})$ is equal to 3.

Degree of $\mathrm{Q}(\mathrm{x})$ is equal to 4.

What is the degree of the $\mathrm{lcm}[(\mathrm{P}(\mathrm{x}), \mathrm{Q}(\mathrm{x})]$ ?

[The extracted part]

Student 1: 4 .

Student 2: 5 .

Ali: $\quad$ Ok, one of you found 4. Another one found 5. Can it be 7, 12 or 16 ?

Student 3: Maximum value is 5, isn't it?

Ali: Why? Please, explain the reason of your answer.

Student 3: There is no else choice.

Student 4: Can it be 7?

Student 5: I think, it cannot be 7 .

Ali: $\quad$ Could you explain why your answer is 7 ?

Student 4: If $\mathrm{P}(\mathrm{x})$ is equal to $(\mathrm{x}+1)^{3}$ and $\mathrm{Q}(\mathrm{x})$ is equal to $\mathrm{x}^{4}$, the $\mathrm{lcm}$ is 7 .

Ali: $\quad$ We can think as $P(x)=x^{3}$ and $Q(x)=x^{4}$ or you think that they have not any same factor. For example,

$\mathrm{P}(\mathrm{x})=\mathrm{x}^{3}$

$\mathrm{Q}(\mathrm{x})=(\mathrm{x}+1)^{4}$

$\operatorname{GCD}[(\mathrm{P}(\mathrm{x}), \mathrm{Q}(\mathrm{x})]=1$

$\operatorname{lcm}[\mathrm{P}(\mathrm{x}), \mathrm{Q}(\mathrm{x})]=\mathrm{x}^{3} \cdot(\mathrm{x}+1)^{4}$

The more little the common factors of the polynomials, the bigger the value of LCM and the smaller the value of the GCD. If the polynomials do not have any common factor, they are relatively prime polynomials. Thus, the degree of the lcm will be seven. So, the biggest value of the LCM will be seven and the smallest values will be four. Which values does GCD have? The greatest value of GCD will be three because we can write one of the polynomials as $x^{3}$. The value of the GCD changes between zero and three.

Ali asked his students to express their different thoughts and responses to encourage class discussions by asking questions. He asked probing questions which would improve the students' ideas by using their responses and tried to understand the reasons underlying students' thinking. 


\section{During the Lesson Study \\ The first cycle of the lesson study}

In the research lesson, Ali asked students to explain their ideas. Thus, he provided for students to compare their ideas with each other and tried to reveal different thoughts. He asked questions to determine the students' ideas about the new concepts. At the beginning of lesson, he first prompted the students to remember their prior knowledge and then asked a question to understand what students think of the symbol of $\sqrt[3]{-}$. By this question, he asked them to make a prediction about a concept which they did not learn before. He encouraged the students to think what the relationship between the bases of the exponential expressions could be, in the equality of two exponential expressions with the same exponents. Then, he discussed about the definition of the radical expressions and the square root of a negative number could be.

Ali: $\quad$ Do you know the expression of $\sqrt[3]{0}$ ?

Students: No.

Student 1: I know.

Ali: $\quad$ Can you explain what you know?

Student 1: We should think "what number of cubes is the number in the root symbol?".

Ali: $\quad$ We can think like that: If the cubes of two numbers are equal $\left[\mathrm{x}^{3}=\mathrm{y}^{3}\right]$, are these numbers [x and y] equal?

Students: Yes

[The extracted part]

Ali: $\quad$ They are always equal.

Student 2: As the exponents of these expressions are odd, they are equal.

Ali: $\quad$ Well. If the squares of two numbers are square? $\left[\mathrm{x}^{2}=\mathrm{y}^{2}\right]$

Students: These numbers are equal.

Students: No, they are not.

Ali: $\quad$ If these $\left[\mathrm{x}^{2}=\mathrm{y}^{2}\right]$ are equal, what can you say?

Students: $\quad \mathrm{x}$ is equal to $\mathrm{y}$ or $-\mathrm{y}$

Ali: $\quad y$ or $-y$, that is $|x|=|y|$

Students: Absolute of these numbers.

[The extracted part]

Ali: What can you say for this expression? $\left[\sqrt{-2^{2}}\right]$

Students: $\quad-2$

Students: It is undefined.

Ali: What do we say?

Students: It is undefined.

Student 2: Absolute of -2 .

Ali: $\quad$ As the square of any number is not negative, $\sqrt{-4}$ is not defined in the set of the real numbers. This is a concept which you do not know.

Ali's questions were appropriate in creating classroom discussion. However, Ali generally listened a few students' responses and only considered the correct answer. The one of the effective questions during the lesson was about how $\sqrt[12]{2^{13}}$ could be written differently. This question helped him to create an effective classroom discussion. He encouraged the students to engage in a discussion by challenging them to explain their ideas. 
Ali: $\quad \sqrt[12]{2^{13}}$ is a response to a question. But this response was not included in the choices. How can you find the response? What can you do?

Student 1: $\quad 2^{\frac{13}{12}}$

Ali: $\quad$ This is not such an answer in the choices, also.

Student 2: $\quad 2^{\frac{26}{24}}$

Student 3: I simplify.

Ali: $\quad$ You cannot simplify $\frac{13}{12}$

Student 4: $\quad 6 \sqrt[12]{2}$

Student 5: $\quad$ Is it $\sqrt{4}$ ?

Ali: I am listening, what else?

Student 6: $\quad 6 \sqrt[12]{2}$

[The extracted part]

Student 3: $\quad \sqrt{4}$, that is, 2 .

Student 4: $\quad \sqrt{4}$, I say the same response.

Ali: $\quad$ It is $\sqrt{4}$ ?

Student 5: $\quad$ Yes, it is $\sqrt{4}$.

Student 7: I think, $\sqrt{2}$.

Student 8: $\quad 2 \sqrt{2}$.

Ali: $\quad$ What is $\sqrt{8}$ ?

Students: $\quad$ It is equal to $2 \sqrt{2}$.

Ali: $\quad$ Because, you can write $\sqrt{8}=\sqrt{4} x \sqrt{2}$. Is it right?

Students: Yes.

Ali: $\quad$ Well then, what is $\sqrt[3]{16}$ ?

[The extracted part]

Student 9: If we write 16 equals to $2^{3} \times 2, \sqrt[3]{16}$ is equal to $2 \sqrt[3]{2}$.

Ali: Well, we can write $2^{3} x 2$ instead of $2^{4}$.

$$
\sqrt[3]{16}=\sqrt[3]{2^{3} x 2}=\sqrt[3]{2^{3}} x \sqrt[3]{2}=2 \sqrt[3]{2}
$$

The cube root of $2^{3}$ is 2 . Now, think $\sqrt[12]{2^{13}}$ similar to this way.

Ali also questioned the reason of the student's idea about the radical expressions with different degrees to be multiplied with each other. So, he provided for the students to connect between the radical expressions and the exponential expressions.

Ali: $\quad$ How do you multiply when the degrees are different?

Student 1: We make the degrees equal to each other.

Ali: $\quad$ Please, multiply $\sqrt{3}$ with $\sqrt[4]{2}$. Why do you have to equalize the degrees for the multiplication? Will be right if you multiply the degrees with each other?

Student 2: Is that so?

Ali: Would it be possible? Why do or do not we multiply the degrees? Or rather, why do we have to equalize the grades?

Student 2: We do not know how much the values increase and how much they decrease when the degrees are different so that their values are exactly equal. 
Ali: $\quad$ Why do we make the grades equal to multiply radical expressions? So let's think your previous learning. Can you multiply $2^{3}$ with $5^{4}$ ?

Students: No.

Ali: $\quad$ Why? Because if the bases were equal we would add the exponents, because the exponents were not equal to each other. This is exactly the reason. Think of it this way least so that we can multiply two numbers: $2^{3} \cdot 5^{4}=10^{4}$ This equation is not true, is it? Similarly, we make the degree of $2^{\frac{1}{4}}$ equal to the degree of $3^{\frac{1}{2}}$. The degrees must be equal so that you can multiply.

\section{The second cycle of the lesson study}

In the research lesson of the second cycle, Ali conducted his lesson by considering his students' ideas. He promted students to express their thoughts by creating a discussion environment in order to reveal the students' thoughts related to different conditions. As can be seen in the following excerpt, he asked the students whether the trigonometric ratios in a right-angle triangle would change in the case that the triangle was larger or smaller provided that the angles remain the same.

Board:

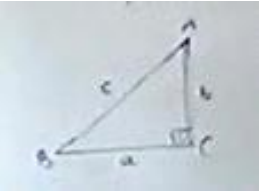

Ali: What if we make the triangle larger or smaller? Will the trigonometric ratios change?

Student 1: No.

Student 2: Yes.

Student 3: Will the ratio change?

Ali: If we decrease the size of the triangle some more, how will the ratio change?

Student 4: It will not change.

Ali: $\quad$ It will not change, because?

Student 4: It's a ratio.

Student 5: Similar triangles.

Ali: $\quad$ In fact, yes, it is the best sentence. These are similar triangles.

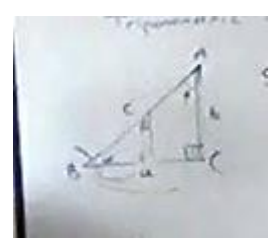

This question was effective for the students to understand that the lengths of the edges of the triangle could be increased or decreased in the same ratio providing that the angles were not changed. Thus, they understood that the trigonometric ratios would not change.

He tried to remind what the units of angles were after he discussed the concept of angle. He first talked about the angles which their units were degree and then the angles which their units were radian. As can be seen in the following excerpt, he asked the students to explain how many radians the circumference of the circle would be. The student expressed the value of the circumference in terms of radian considering that the radius of the unit circle is 1 and the circumference of the circle is $2 \pi r$. He questioned the reason of the student's answer to this question and extended the student's answer.

Ali: $\quad$ How many radians will the circumference of the circle be?

Student 1: It will be $2 \pi$.

Ali: Why?

Student 1: The value of the circumference is $2 \pi r$ and the radius is 1 . 
Ali: Well. You have already known the circumference of a circle. It is $2 \pi r$.

If we think that the value of 1 radius-arc is 1 radian, we can find by dividing the value of the circumference by $r$.

$$
\frac{2 \pi r}{r}=2 \pi
$$

However, Ali did not encourage his students to create ideas that could be alternative or opposite to each other's ideas and did not prompt them to produce ideas or make explanations about his own expressions.

Ali conducted the revision lesson by taking into consideration the students' ideas as he did in the research lesson. He continually asked his students' ideas about concepts and their properties. As can be seen in the following excerpt, when the student who solved a problem with trigonometric ratios in an unpractical way, he encouraged the students to think about whether a proper and a short solution would be possible.

Board: $\quad$ If $\frac{2}{\cos x}=\frac{1}{\sin x}$, what is the value of $\left(\frac{\sin x+\cos x}{\tan x}\right) \cdot \cot x$ ? [A student came to the board to solve this question.]

Ali: $\quad$ How will you solve?

Student: I will cross-multiply.

Ali: Well. What will you find?

Student: $\quad 2 \sin x=\cos x$

Ali: What will you divide the expressions in the equation for reach the solution quickly?

Student: It is not necessary to divide them by anything. We can substitute $2 \sin x$ for $\cos x$ and $\sin x / \cos x$ for $\tan x$, and it is $\frac{1}{2}$ by using this equality $\frac{2}{\cos x}=\frac{1}{\sin x}$.

Ali: $\quad$ How will you find $\cot x$ ?

Student: It is equal to $\frac{\cos x}{\sin x}$. I think, I will find the result by this way.

Ali: $\quad$ Ok, can you solve?

Student: $\quad \frac{3 \sin x}{\frac{\sin x}{\cos x}} \cdot \frac{\cos x}{\sin x}$ [The student did not reach the solution]

Ali: You can think whether a more practical solution way.

Since the student could not find the solution, Ali asked it to the all students and prompted them to think differently. During the revision lesson, there was no discussion, as students often gave appropriate responses.

\section{The third cycle of the lesson study}

In the research lesson of the third cycle, Ali continually tried to understand his students' ideas while finding the coterminal angle and solving questions. Instead of lecturing, he first asked the students' ideas and made explanations based on their ideas. Ali not only focused on their ideas but also tried to reveal the underlying reasons of their ideas. As can be seen in the following excerpts, he asked the reason of the student's solution to the question which required to find the value of cosine of an angle by using a triangle's properties.

Ali: Please, can you solve this question?

Student:

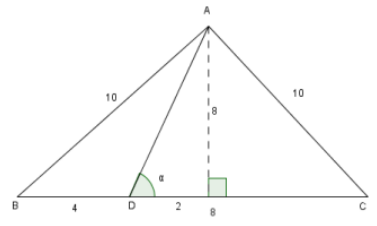

Ali: $\quad$ How did you do?

Student: $\quad$ I drew a perpendicular line at the point on the this side [showing [BC]). This length is 2 .

Ali: Why?

Student: $\quad$ Because, the half of 12 is 6 .

Ali: $\quad$ Why did you draw the perpendicular line? 
Student: Because there is a isosceles triangle. This line bisects the base and so, a right angle triangle is created.

The student drew a perpendicular line at the top of the triangle through the point on the edge and determined the edge lengths by considering the properties of the isosceles triangle. Ali asked this student to elaborate the solution. Thus, he helped the student to gain awareness of what he did by pushing him to explain the process.

As can be seen in the following excerpt, Ali asked questions about a student's solution in the example of finding the coterminal angle of a negative angle with degrees and thus, he allowed the other students to understand what the student did. By this action, Ali had the all students to think about the student's ideas.

Ali:

Find the coterminal angle of $-2480^{\circ}$, please. ... What does the negative sign mean?

The student on the board:

\begin{tabular}{r|c}
2480 & 360 \\
2160 & 6
\end{tabular}

Ali:

What is this? Is the coterminal angle $320^{\circ}$ ? How many degrees does the coterminal angle have?

The student on I will calculate and then I will say.

the board:

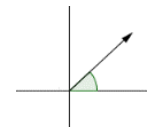

Ali: Draw a unit circle. How do you put the arrow mark?

The student on the board:

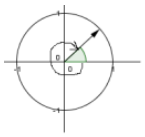

Ali:

Right? [asking to the class]

Students: $\quad$ No.

Students: Right.

Ali:

No.

If the coterminal angle of an angle is $\alpha, 0<\alpha<360$

It has to be positive. She divided -2480 by 6 and she did not find the coterminal angle. She found that the remained was -320 when she subtracted perigon angles she went around the circle. Right?

Students: $\quad$ Yes.

Ali: $\quad$ That is, the coterminal angle is +40 .

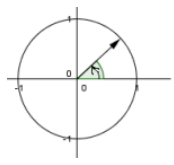

It is the positive one.

The student on If we find a negative angle, we will add 360.

the board:

Ali:

I will tell what you can do, please listen carefully because you can make mistakes about this. Your friend said something good. She said "I divided 2483 by 360 and I know this angle is negative. If we divide it by 6 , the remaining is 6 ". That is, the remaining angle is negative, the coterminal angle of this angle is $40^{\circ}$. Because, the coterminal angle is positive. If you add the 360 to -320 , it is $40^{\circ}$. You can find the coterminal angle. 
In the revision lesson of the third cycle, Ali shaped his teaching in the direction of the students' ideas and tried to reach the ideas of the students by asking questions about finding the coterminal angle. As can be seen in the following excerpt, Ali asked the students to product alternative ideas to the solution which was done in finding the coterminal angles of angles with radian.

Ali: What is the coterminal angle of $4 \pi$ ?

Students: Zero.

Ali: $\quad$ What is the coterminal angle of $7 \pi$ ?

Student 1: $\pi$

Student 2: If we divide it by $2 \pi$, it remains $\pi$.

Board: [Ali wrote the student's expression.]

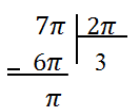

[The extracted part]

Ali: [After he asked the coterminal angle with radian like $\mathrm{k} \pi, \mathrm{k}$ an integer.] What is the coterminal angle of $\frac{25 \pi}{3}$ ?

Student 3: We can find it by dividing $2 \pi$.

Student 4: It is multiplied with $\frac{12}{3}$ and there remains $\frac{1}{3}$.

Ali: $\quad$ Come to the board and explain it.

Student 4: $\quad \frac{25 \pi}{3} \mid 2 \pi$

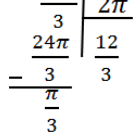

Ali: $\quad$ That's great! Ok, what else can you find the multiples of $2 \pi$ ?

Student 5: We can write it as integer and improper fraction.

Ali: $\quad$ Ok, we will divide it by 2 .

Student 5: $\quad \frac{24 \pi}{3}=8 \pi$ is integer part and $\frac{\pi}{3}$ is fraction part.

[The extracted part]

Ali: $\quad$ We will subtract the multiples of $2 \pi$ from it. That is, we will make out the acute angle if we substract the multiples of $2 \pi$ from $\frac{25 \pi}{3}$.

[The extracted part]

How many $2 \pi$ can we write?

$\frac{25 \pi}{3}=4.2 \pi+\frac{\pi}{3}$

\section{After the Lesson Study}

Ali generally tried to reveal his students' thoughts while asking a question. Additionally, he questioned other students' ideas when the student on the board could not solve the question. He asked the student, who used from the half-angle formula of sine for solving the problem, to explain the reason for her solution, thus, he provided the other students to revise their own ideas.

Board:

$$
\begin{aligned}
& 0<\alpha<\frac{\pi}{2} \\
& \cot \frac{\alpha}{2}=\frac{1}{a} \\
& \sin \alpha=?
\end{aligned}
$$

[The extracted part] 
The student on I wrote sin $\alpha$ by using the half-angle formule

the board:

Ali:

Why did you write so?

Ali questioned the reasons of the student's solution. Thus, he provided for the all students to understand the solution and to compare the solution to their own thoughts.

Board:

$\sin 10 \cdot \cos 20 \cdot \sin 30 \cdot \cos 40=$ ?

The student on the 2. $\cos 10 \cdot \sin 10 \cdot \cos 20 \cdot \sin 30 \cdot \cos 40$ board:

2. $\cos 10$

Ali:

Why did you multiply with $2 \cos 10$ and divide by $2 \cos 10$ ?

\section{DISCUSSION AND CONCLUSIONS}

In this study which a mathematics teacher's actions triggering different thoughts was examined, it was seen that as the lesson study cycles progressed, the teacher had actions involving different and effective approaches.

Before the lesson study, the teacher generally asked questions to understand the students' thoughts. However, his approaches were limited with the specific actions. Ali prompted the students to think by creating discussion environment and explained the students' ideas. Kula Ünver and Bukova Güzel (2016) stated that teachers could enable students to understand suggested thoughts, reasons of different thinking and another ideas by explaining students' ideas. Parallel to this, in our study, explaining and expanding a student's thinking was important in rethinking of students' own ideas by supporting their understanding and associating to different ideas. Ali triggered the students' thinking by forming discussion environments and asking the questions requiring making connections.

In the first cycle of the lesson study, Ali explained and expanded their students' ideas. Since the teachers discussed on the concepts and they planned the lesson by achieving a consensus during the planning stage, they involved in interactions supporting each other's approaches. Thus, they focused on the concepts more while they were explaining their ideas. In their study, Meyer and Wilkerson (2011) expressed that the facilitators provided for the teachers to consider the concepts in case that some teachers who participated in lesson study focused on the implementation of the lesson. In the meetings during our study, the researchers' questions and the group talks supported for the teachers to focus on the concepts. Thus, Ali considered the students' ideas in the teaching process. Encouraging the students to think of a concept which they did not know before and creating a discussion environment related to the new concept became important for the students to see and evaluate different ideas.

In the second cycle of the lesson study, Ali had approaches prompting the students to think differently. He asked questions and created discussion environment to reveal the students' ideas and encouraged them to use different solution ways. However, he could not use the different solutions as effective opportunities. In the process of discussing the definition of radian, he could have asked his student to relate another student's response regarding the definition. Also, he could have asked other students to explain their ideas and to interpret different ideas. As Ali focused on only one student's reasoning, possible thinking process which would be revealed by the interactions was not triggered. Parallel to this, if he had provided for the students to interact with the other students while solving questions, he could have created discussion environment for revealing different thinking. In the classroom, if the teacher asks for a student to explain and justify his/her ideas, he may support all students for understanding that idea and gaining different point of views.

During the lessons of the third cycle, Ali had approaches similar to those in the second cycle. In the process of the lesson study process, it was seen that divergent questions triggered divergent thoughts while the questions which could be solved in similar ways did not trigger different ideas and interpretations. Especially, the questions of "How to solve this question in different ways?", "How to explain this in a different way?", "You can think whether a more practical solution way", "What else can you find the multiples of $2 \pi$ ?" etc. were effective in providing teacher-students interactions and in triggering different thinking. Additionally, the questions relating the concepts and topics with each other such as relating exponential expressions with radical expressions, conversion between degree and radian supported different ideas.

By the lesson study, Ali became to consider the students' different thinking more. Ball and Bass (2003) have emphasized that in the context of the professional development programs, the environments which 
prompt teachers to share their knowledge and ideas with their colleagues should be designed. Ali gave enough time for the students to think by the lesson study. This approach is easy to reflect on the teaching but it is generally ignored. Blosser (2000) stated that teachers should give enough time for the students to think and response appropriately. Parallel to this, Lee (2006) expressed that teachers supported for students to find and discuss different solution ways by giving enough time.

Ali questioned their students more after the lesson study process. Thus, he triggered to reveal divergent ideas. We can say that teachers' observations on their colleagues' teaching and their discussions with each other affect their teaching. The processes which teachers collaboratively study with their colleagues and the researchers such as lesson study are effective for making teachers' teaching approaches powerful.

\section{Disclosure statement}

No potential conflict of interest was reported by the authors.

\section{Notes on contributors}

Aytug Ozaltun Celik - Pamukkale University, Turkey.

Esra Bukova Guzel - Dokuz Eylul University, Turkey.

\section{REFERENCES}

An, S., Kulm, G., \& Wu, Z. (2004). The Pedagogical content knowledge of middle school mathematics teachers in China and the U.S. Journal of Mathematics Teacher Education, 7(2), 145-172. https://doi.org/10.1023/b:jmte.0000021943.35739.1c

Ball, D. L., \& Bass, H. (2003). Toward a practice-based theory of mathematical knowledge for teaching. In B. Davis \& E. Simmt (Eds.), Proceedings of the 2002 annual meeting of the Canadian Mathematics Education Study Group (pp. 3-14). Edmonton, Alberta, Canada.

Blosser, P. (2000). How to ask the right questions. Arlington, VA: National Science Teacher Association.

Cengiz, N. (2007). What allows teachers to extend student thinking during whole group discussions? (Unpublished doctoral dissertation), Western Michigan University, Kalamazoo, MI.

Coffey, J., Edwards, A. R., \& Finkelstein, C. (2010). Dynamics of disciplinary understandings and practices of attending to student thinking in elementary teacher education. ICLS, Volume 1, (pp. 1040-1047), International Society of the Learning Sciences.

Fetterly, J.M. (2010). An exploratory study of the use of a problem-posing approach on pre-service elementary education teachers' mathematical creativity, beliefs, and mathematics anxiety (Unpublished doctoral dissertation), College of Education, The Florida State University, Tallahassee, FL.

Franke, M. L., Webb, N. M., Chan, A. G., Ing, M., Freund, D., \& Battey, D. (2009). Teacher questioning to elicit students' mathematical thinking in elementary school classrooms. Journal of Teacher Education, 60(4), 380-392. https://doi.org/10.1177/0022487109339906

Hill, H. C., Ball, D. L., \& Schilling, S. G. (2008). Unpacking pedagogical content knowledge: Conceptualizing and measuring teachers' topic-specific knowledge of students. Journal for Research in Mathematics Education, 39(4), 372-400.

Hurd, J., \& Licciardo-Musso, L. (2005). Lesson study: Teacher-led professional development in literacy instruction. Language Arts, 82(5), 388-395.

Kula Ünver, S., \& Bukova Güzel, E. (2016). Conceptualizing pre-service mathematics teachers' responding to students' ideas while teaching limit concept. European Journal of Education Studies. 33-57. https://doi.org/10.5281/zenodo.19307

Lee, K. (2006). Teachers' knowledge of middle school students' mathematical thinking in algebra word problem solving (Unpublished doctoral dissertation), Oregon State University, Corvallis.

Marks, R. (1990). Pedagogical content knowledge: from a mathematical case to a modified conception. Journal of Teacher Education, 41(3), 3-11. https://doi.org/10.1177/002248719004100302 
Meyer, R. D., \& Wilkerson, T., L. (2011). Lesson study: The impact on teachers' knowledge for teaching mathematics. In L. Hart, A. Murata \& A. S. Alston (Eds.), Lesson study research and practice in mathematics education: Learning together (pp. 15-27). Dordrecht: Springer. https://doi.org/10.1007/97890-481-9941-9_2

Özaltun Çelik, A., \& Bukova Güzel, E. (2018). Describing lesson study designed for improvement of mathematics teachers' knowledge of student thinking. International Journal for Mathematics Teaching and Learning, 19(2), 176-204. https://doi.org/10.22342/jme.8.2.4144.207-218

Patton, M. Q. (2002). Qualitative research and evaluation methods (3rd ed.). Thousand Oaks, CA: Sage.

Perry, R. R., \& Lewis, C. C. (2009). What is successful adaptation of lesson study in the US?. Journal of Educational Change, 10(4), 365-391. https://doi.org/10.1007/s10833-008-9069-7

Shahrill, M. (2013). Review of teacher questioning in mathematics classrooms. International Journal of Humanities and Social Science, 3(17), 224-231.

Van Zoest, L. R., Stockero, S. L., \& Kratky, J. L. (2010). Beginning mathematics teachers' purposes for making student thinking public. Research in Mathematics Education, 12(1), 37-5. https://doi.org/10.1080/14794800903569832

Wicks, R., \& Janes, R. (2006). Uncovering children's thinking about patterns: teacher-researchers improving classroom practices. In S. Z. Smith, D. S. Mewborn, \& M. E. Smith (Eds.), Teachers engaged in research: inquiry into mathematics classrooms, grades pre-k-2 (pp. 211-236). Greenwich, CT: Information Age Publishing.

Yoshida, M. (1999). Lesson study: A case study of a Japanese approach to improving instruction through schoolbased teacher development (Unpublished doctoral dissertation). University of Chicago, Chicago, USA. 